\title{
Familia y escuela, un mismo equipo
}

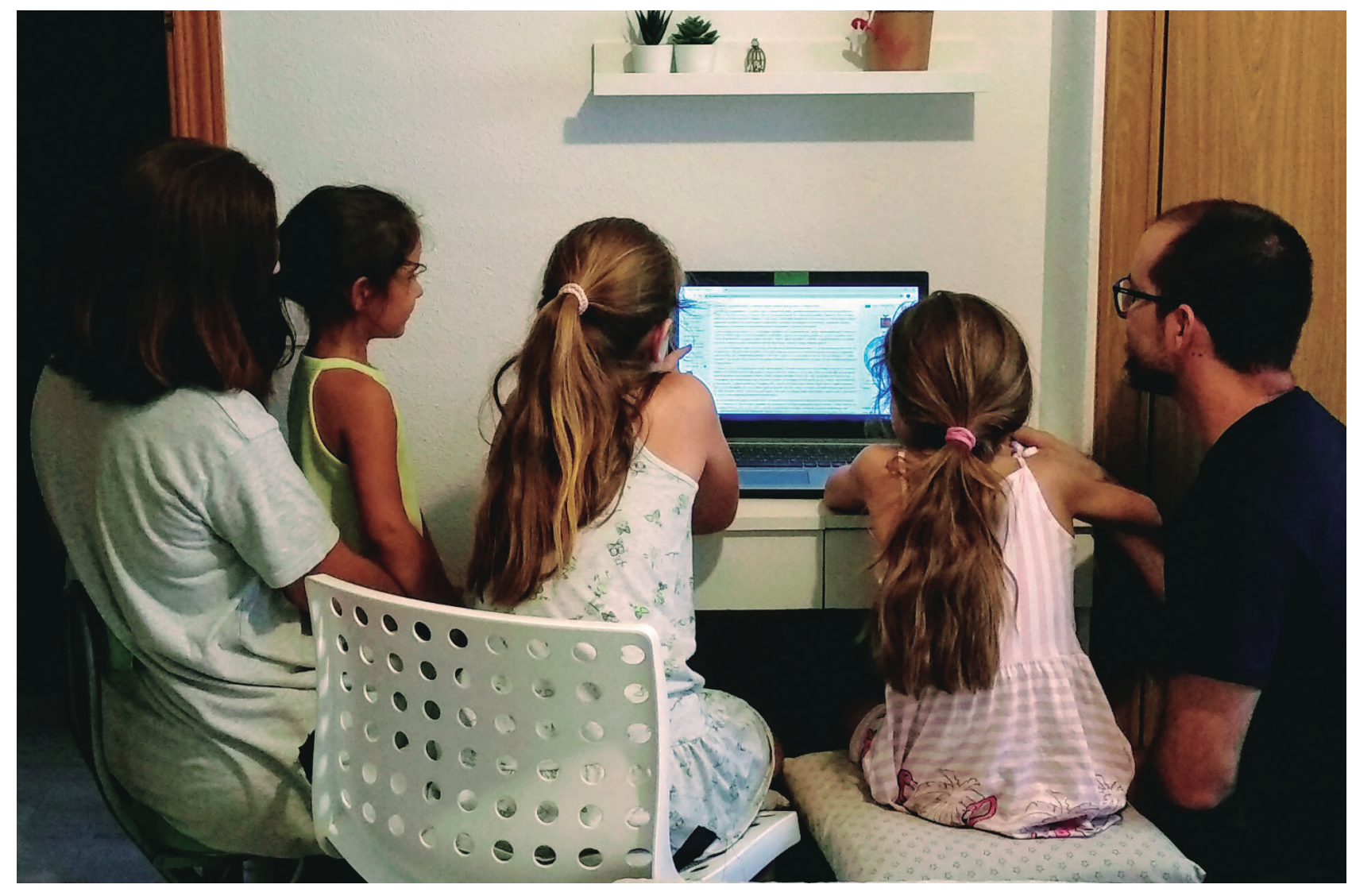

Ser maestro implica estar abierto a la adaptación y al aprendizaje constantemente, en nuestra práctica diaria. Pero lo cierto es que la vorágine muchas veces nos aleja de la necesidad de parar a escuchar. La COVID-19 está siendo nuestra gran oportunidad para

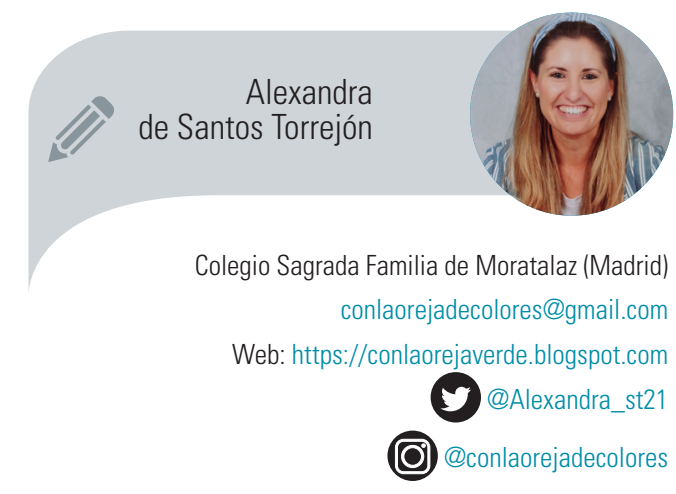
echar el freno y mirar con más atención que nunca a nuestros alumnos y sus familias. Este artículo pretende recoger mi experiencia de adaptación a mis alumnos y sus familias para trabajar con ellos de acuerdo a sus intereses, necesidades y experiencias de motivación. 
La palabra "familia" tiene un significado que a cualquiera de nosotros nos despierta una sonrisa, una sensación de ternura, un recuerdo agradable, un espejo en el que mirarnos o incluso nuestro gran foco a lo largo de nuestra vida. Por otro lado, la palabra "escuela" representa el aprendizaje, la amistad, el encuentro, el crecimiento, la base de una sociedad desarrollada. Por tanto, unir familia y escuela debería ser el eje central de todos los docentes, de todos nosotros. Debería ser nuestro gran objetivo común.

A lo largo de mi experiencia profesional, he centrado muchos de mis esfuerzos en encontrar esta unión de los dos elementos clave para el desarrollo de mis alumnos, de los niños. Y es desde ahí, desde mi experiencia, desde donde puedo afirmar que los resultados son siempre maravillosos, que las familias tienen mucho que decir y mucho que aportar, que les gusta sentir que forman parte del proyecto educativo de sus hijos en el centro en el que estudian, que les gusta implicarse y participar y que el desarrollo de los pequeños siempre es más positivo cuando realizamos un verdadero trabajo en equipo.

La cercanía, el cara a cara y las constantes tutorías llegan incluso a sanar heridas y a corregir muchas dificultades. Pero en marzo de 2020 este "tú a tú" se vio interrumpido de una forma brusca y muy inesperada por un virus. Un virus que aumentó la angustia y la tensión en las familias. Un virus que hizo que en muchos hogares crecieran las dudas y la incertidumbre sobre cómo sacarían la situación adelante. Un virus que cortó ese contacto diario con alumnos y familias y que nos obligó a que las pantallas fueran las auténticas intermediarias.

Ante una situación tan excepcional y dramática a la vez, ¿qué podía hacer? Desconocía por completo las condiciones laborales de las familias de mis alumnos, así como los medios tecnológicos de los que disponían en su casa o de sus preferencias a nivel organizativo. Por tanto, ¿qué es lo primero que tenía que hacer? Preguntar. Parece una respuesta muy
Dispositivos tecnológicos en casa

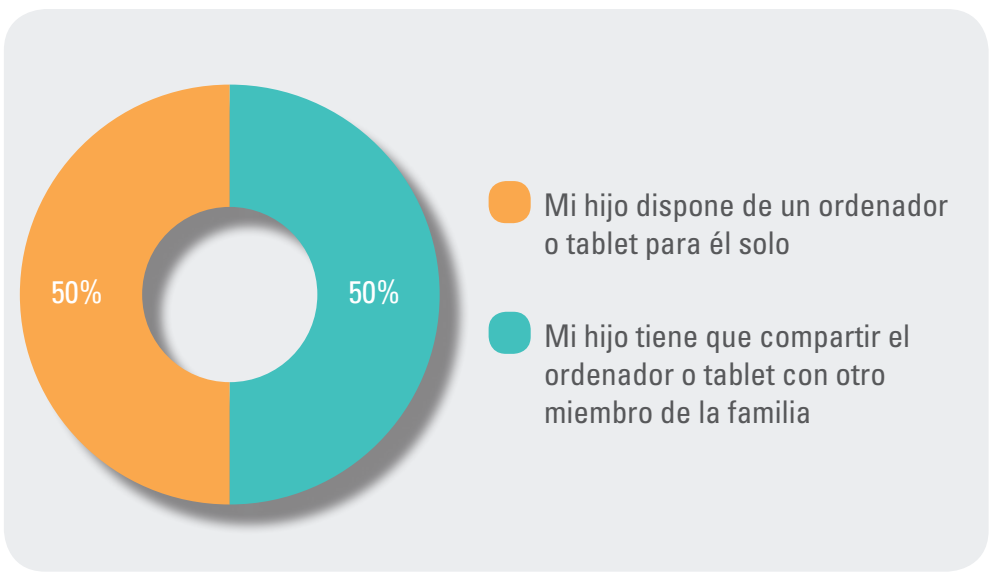

Tiempo empleado por mi hijo en las tareas

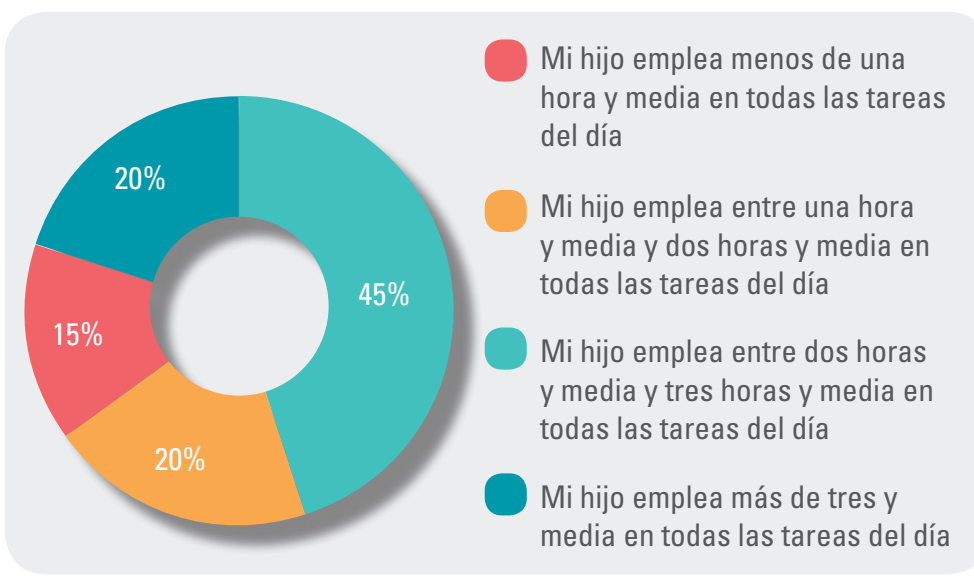

obvia, pero no hace falta más que una sencilla mirada a ambos lados para darnos cuenta de que somos mucho más de asumir que de preguntar. Así, elaboré un cuestionario de ocho preguntas para conocer la situación real de cada una de las familias de mi clase y poder organizar mi trabajo de tal modo que favoreciese y no entorpeciese la vida en sus hogares. Afortunadamente, muchos de mis compañeros comprendieron que era una buena idea y conseguimos que el "virus de preguntar" se extendiese con más rapidez que el contagioso virus que nos había encerrado en casa.

Aparentemente pueden resultar preguntas sencillas, pues se centraban en la conexión a internet o en el tiempo empleado por sus hijos en las tareas; pero en ese momento fueron más que necesarias y supusieron una ayuda infinita en una situación de caos, donde adultos y 


\section{¿QUÉ NECESITAN LAS FAMILIAS?}

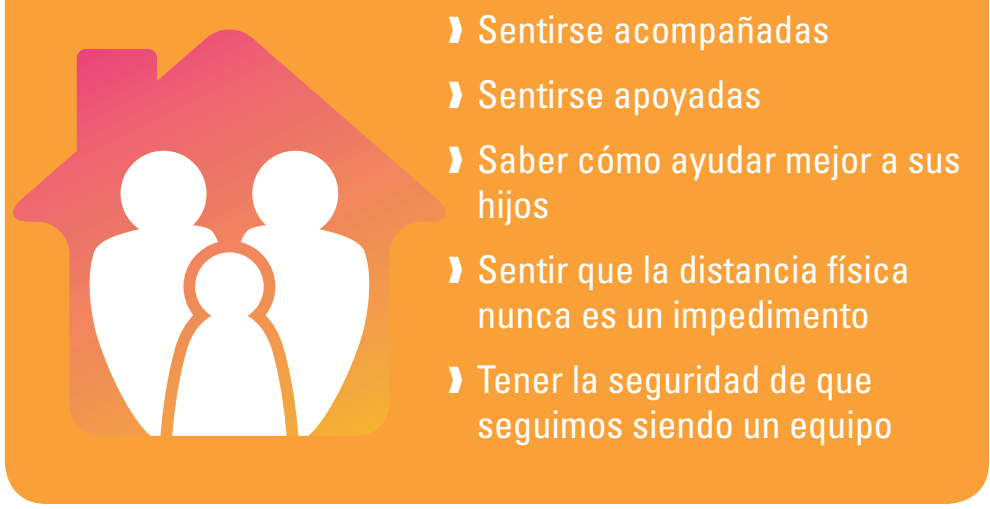

niños estábamos tratando de asimilar a lo que nos enfrentábamos. Las respuestas de las 20 familias (de un total de 22) que participaron fueron fundamentales en la organización de mi trabajo y labor con los pequeños desde el primer momento.

Sin embargo, a los pocos días me di cuenta de que esta información recogida en ese primer cuestionario solo respondía a las circunstancias logísticas, pero dejaba a un lado las verdaderas necesidades de mis alumnos y sus familias. ¿Qué era lo que más necesitaban de mí? ¿Aprender tal o cual contenido académico o sentir que su maestra seguía estando a su lado y formando parte de sus vidas, aunque no le pudiesen ver cara a cara? Yo tuve la respuesta clara desde el primer momento. Así, mi principal objetivo desde que comencé a ser "telemaestra" fue intentar mostrar esta cercanía que me caracterizaba en el aula, que mis alumnos y sus familias sintieran que estaba cerca de ellos. Los correos electrónicos y las llamadas telefónicas empezaron a tener un papel esencial, ya no solo en el aprendizaje de los pequeños, sino en el bienestar de las familias. En muchas casas se estaba despertando un estrés y un caos familiar muy difícil de asimilar. Varias familias se ponían en contacto conmigo solo para transmitirme sus preocupaciones, para compartir conmigo cómo se sentían. Ya no había preguntas como: ¿qué puedo hacer para que Noelia mejore en los problemas de matemáticas? O ¿cómo ayudo a que Candela adquiera mejor fluidez en su lectura? El mundo nos estaba ofreciendo su cara B y nos estaba haciendo replantearnos las verdaderas prioridades. Estaba transformando las preguntas. Ahora las preguntas eran: ¿qué puedo hacer para que Daniela esté más tranquila? O ¿cómo consigo que a Carla se le vaya la ansiedad que le despiertan las tareas?

Las verdaderas necesidades de las familias eran sentirse acompañados, contar con mi apoyo en el trabajo que muchos de ellos estaban realizando con sus hijos. Algunos incluso me lanzaron preguntas metodológicas sobre cómo podían ayudar mejor a los pequeños. Necesitaban sentir que, a pesar de la distancia física, seguíamos siendo un equipo y seguíamos compartiendo el mismo objetivo: el desarrollo de los niños.

A medida que fueron pasando los días, los alumnos fueron mostrando desánimo y la calidad de sus tareas empezó a bajar. La cara de alguno de ellos cuando les preguntaba a través de las videollamadas sobre cómo lo llevaban era más que aclaratoria. A su vez, los correos de las familias contenían cada vez más preocupaciones. Así que decidí hacer otro alto en el camino. Era el momento de mirar con un poco más de perspectiva. Era el momento de frenar y analizar cómo podía conseguir que siguiesen alegres y motivados las últimas semanas de curso que aún nos quedaban por delante. Era el momento de volver a preguntar.

El objetivo de este segundo cuestionario de 15 preguntas era muy diferente del primero. Esta vez, el cuestionario iba dirigido a los alumnos y no a sus familias (aunque les pedí su colaboración para que las respuestas de los peques tuviesen sentido). Quería conocer cómo se sentían, qué tipo de tareas estaban disfrutando más, qué asignatura les estaba costando más aprender... Diferentes cuestiones que me guiarían en mi actuación metodológica con el fin de contribuir a su aprendizaje de la forma que realmente necesitaban y reducir así esa carga familiar. Las familias no solo se estaban encargando de que sus hijos hiciesen las tareas, sino de que se sentasen y concentrasen en las mismas para poder entregarlas a tiempo o incluso explicarles contenidos que no conseguían comprender a través de las explicaciones 
de sus profes. Por ello, consideré que adecuando la forma de mis actividades a sus intereses, ayudaría a ambas partes y permitiría una mayor autonomía en mis alumnos y menos presión en sus familias.

El resultado completo del cuestionario puede consultarse aquí https://revistas. comillas.edu/index.php/padresymaestros/familia-escuela-equipo

Como se puede comprobar en las imágenes, muchas de las respuestas son bastante significativas y ofrecen un panorama más realista. Las respuestas de mis alumnos no solo me ayudaron a entender qué necesitaban, sino que me permitieron conocerles mejor. ¡Qué importante es preguntar para saber!

En base a los gráficos de sus respuestas, me gustaría destacar aquí las que fueron mis conclusiones más significativas de este cuestionario y su relevancia en el funcionamiento de las semanas posteriores al mismo.

1. A los alumnos les gusta dar su opinión. Su voz y su voto son fundamentales. Al igual que sus familias, tienen mucho que decir y necesitan sentirse escuchados.

2. Disfrutar o aprender más o menos una asignatura está directamente relacionado con el tipo de tareas y metodología que se aplique en la misma.

3. Los libros de texto no favorecen el aprendizaje ni la motivación de los pequeños.

4. Las actividades más creativas (que requerían una participación más activa de los alumnos) y los retos cognitivos eran claramente sus favoritas. Estableciendo así un gran referente de cara al proceso de enseñanza-aprendizaje.

5. Los alumnos valoran enormemente la personalización. Los vídeos o tareas preparados directamente por mí para ellos generaban un efecto más motivador y alentador. Algunos incluso llegaban a aprendérselos de memoria y a utilizar las expresiones que yo misma empleaba.

6. El apoyo emocional es esencial para su aprendizaje. Las videollamadas fue-
El maestro pedirá a sus alumnos que representen a su familia. Pueden hacerlo de diversos modos, como cada alumno se sienta más cómodo; así, también atendemos a las inteligencias múltiples y conocemos un poquito más a nuestros pequeños. Pueden escribir un cuento, hacer un dibujo, moldear plastilina, preparar una obra de teatro... cualquier idea es válida. Lo que verdaderamente importa es que estas representaciones tengan un mismo objetivo: que cada alumno reflexione sobre la realidad de su hogar y la comparta con su maestro.

Es necesario que estas representaciones no atiendan exclusivamente a la parte más física y visual como el número de miembros en su familia o cómo son físicamente cada uno de ellos. También tienen que representar las cosas que les gusta hacer con cada uno, qué actividades hacen todos juntos, con quién hacen las tareas del cole, qué rutinas tienen en casa, con quién se sienten más a gusto, con quién comparten sus problemas... La profundidad de las preguntas dependerá siempre de la edad de los niños. Pero es una actividad perfectamente válida para cualquier curso.

También puede ser muy interesante que las familias realicen esta misma actividad con sus hijos en casa, pero respecto al cole. E incluso me atrevería a añadir que sería enormemente enriquecedor que cada miembro de la familia comparta su experiencia: los padres, de su trabajo; y los hijos, del cole. Generaría un clima de confianza en el hogar que puede ser muy valioso para afianzar vínculos, crear algunos nuevos y para detectar posibles dificultades o puntos de conflicto.

¿Con qué materiales aprendes más?

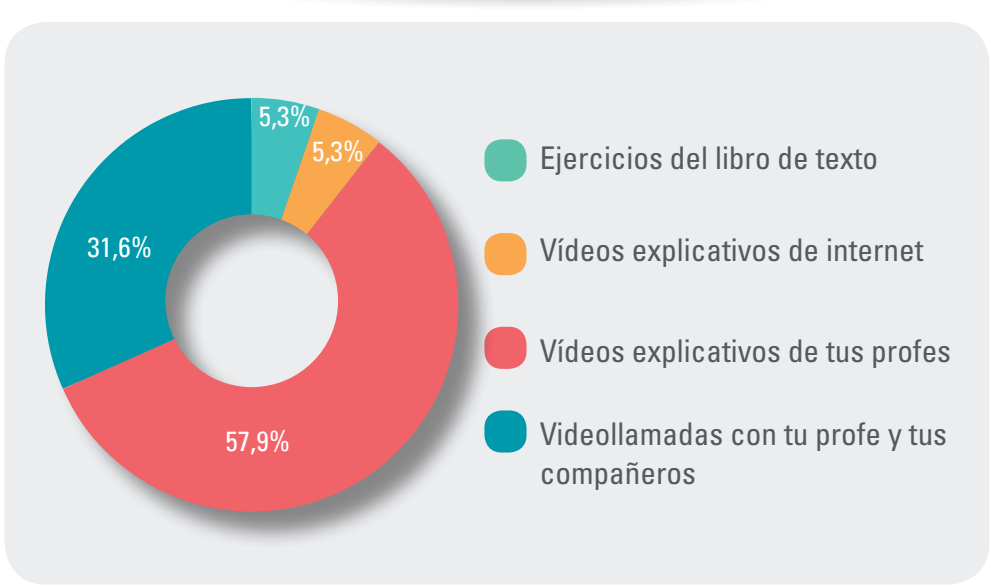

¿Qué tipo de tareas te hace menos ilusión recibir?

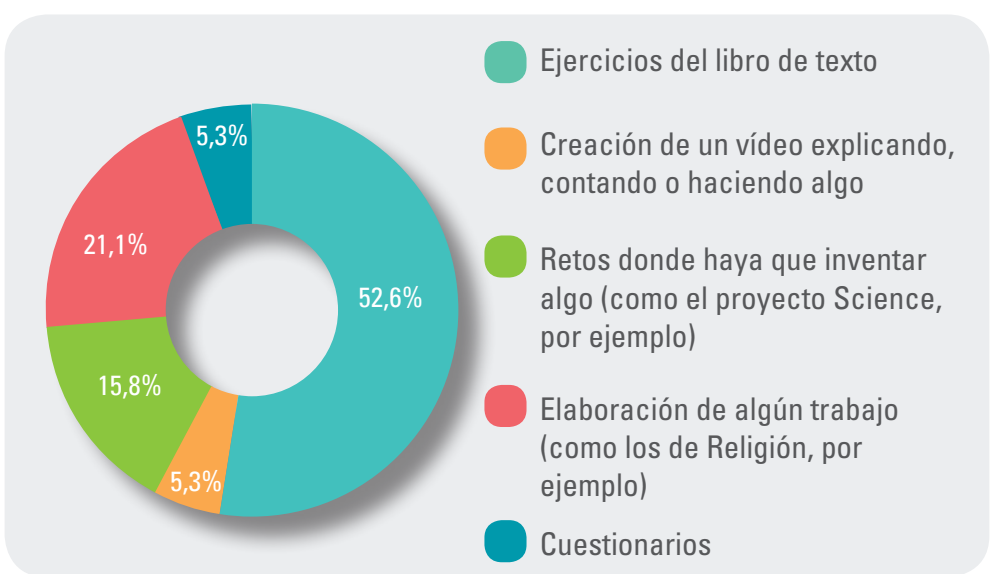




\section{conctosiones CONCLUSIONES DE MI EXPERIENCIA COMO TELEMAESTRA}

1. A los alumnos les gusta dar su opinión

2. Disfrutar o aprender una asignatura está relacionado con la metodología que se emplea

3. Los libros de texto no favorecen el aprendizaje

4. Las actividades más creativas y los retos cognitivos son las actividades favoritas de los alumnos

5. Los alumnos valoran enormemente la personalización

6. El apoyo emocional es esencial para su aprendizaje

7. Si te atreves a preguntar, tienes que ser flexible y adaptarte a las respuestas

8. Los alumnos han aprendido a valorar más el colegio

9. Las familias agradecen la capacidad de adaptación

10. Implicar a las familias en las actividades fue un éxito

ron un elemento clave no tanto a nivel académico como emocional. Ver las caras de sus compañeros y de su profe, enseñar sus mascarillas o contar cómo fue la primera vez que salieron a la calle después del confinamiento era, sin duda alguna, lo más importante para ellos.

7. Como maestra, si me había lanzado a preguntar, tenía que mostrarme flexible para adaptarme a sus respuestas y modificar determinadas tareas. Tenía que ofrecer a mis alumnos y sus familias un nuevo planteamiento. $Y$ si no, no haber preguntado...

8. Los alumnos han aprendido a valorar muchísimo más el cole y todo lo que viven en él. Todos ellos, sin excepción, lo han echado muchísimo de menos.

9. La gran mayoría de las familias agradecieron sinceramente este cuestionario y valoraron la capacidad de adaptación.

10. Implicar a las familias en alguna de las actividades les permitió disfrutar de momentos juntos de una manera diferente. $Y$ muchos de los resultados de estas tareas son realmente especiales.
Aunque este cuestionario se realizara en un contexto muy particular, considero que las respuestas de los alumnos y las conclusiones que de ahí se pueden obtener son perfectamente extensibles a nuestra realidad en el aula. Para mí son el claro ejemplo de lo importante que es preguntar, de lo importante que es que cada uno tenga su espacio, su voz y su voto. Cualquier cambio educativo o proceso innovador debe pasar por preguntar a los protagonistas del proceso de aprendizaje sobre sus preferencias, sus gustos y sus motivaciones.

Las últimas semanas de curso (posteriores a este cuestionario) fueron mucho mejor. Las actividades volvieron a ganar calidad y los ánimos y la alegría ocuparon de nuevo su lugar. La carga de trabajo también se redujo, para no permitir que el cansancio ganara la batalla.

Escuchar y atender las sugerencias de las familias generó un vínculo entre todos, que nos llevó incluso a grabar un videoclip de una canción muy especial todos juntos (cada uno desde su casa, claro). Ese vídeo no es más que el reflejo de haber estado en una misma sintonía y de habernos sentido uno.

Después de una experiencia tan intensa de aprendizaje para todos, me gustaría destacar aquí los elementos clave que yo he detectado para mejorar la relación entre las familias y la escuela.

入 Si las familias se sienten implicadas, el proceso de adaptación es más sencillo. Pero no tenemos que esperar a que llegue un virus. Desde el primer día de clase tenemos que hacer que las familias se sientan parte de un proyecto común.

入 Es necesario preguntar a las familias. No podemos asumir sus circunstancias sin ofrecer nuestra comprensión y adaptabilidad. Este virus ha demostrado que la brecha tecnológica o incluso la brecha social siguen siendo una realidad. Debemos atender a todas las necesidades que se nos presenten en nuestro grupo y, para ello, es fundamental conocerlas a través de las preguntas. 
X

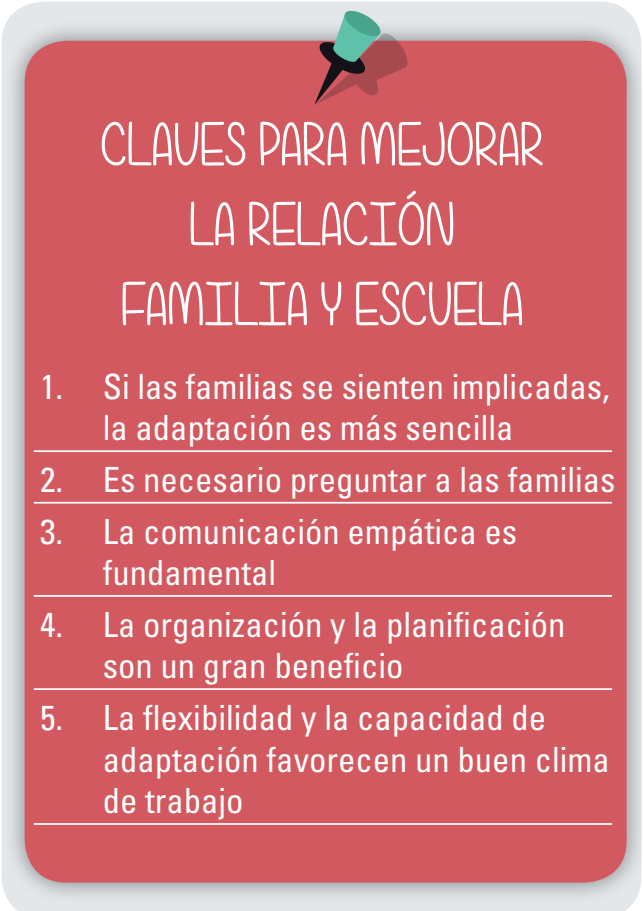

7 La comunicación constante es fundamental; pero no una comunicación cualquiera, debe ser una comunicación empática. Debemos mostrarnos cercanos con las familias. Tenemos que ofrecer nuestra comprensión hacia sus particularidades y atender sus circunstancias para el bienestar de los pequeños.

入 La organización y una buena planificación suponen un gran beneficio y ayuda para las familias. Especialmente en una situación crítica como la que hemos vivido, las familias deben saber qué esperar, qué tienen que aprender sus hijos, cómo vamos a organizar el trabajo. Es fundamental para mantener un buen clima tanto en el aula (aunque sea virtual) como en casa.

- Ser flexible y tener capacidad de adaptación es lo que genera un buen clima de trabajo y que todos los agentes sientan que forman parte del proceso. Tenemos que saber hacer autocrítica, valorar pros y contras y observar cómo están funcionando las cosas. No podemos ser rígidos, cerrar los ojos y mantenernos en esquemas obsoletos.

\section{ÁQORA DE DROFESORES}

A lo largo de mi trayectoria profesional he realizado varias actividades con las familias de mis alumnos y considero que un punto fundamental de mejora son las reuniones de padres de principios y mediados de curso. El proceso de innovación debe prestar atención también a estos momentos en los que padres y docentes nos unimos. No pueden seguir siendo monólogos aburridos con un PowerPoint eterno en los que el tutor repite muchas cosas que las familias ya saben. Tenemos que ofrecer a las familias nuestra mejor versión y ganarnos su confianza para desarrollar un buen trabajo de equipo. Creo que los equipos directivos deberían prestar más atención a este punto y favorecer que sus claustros se atrevan a dar un vuelco a estas reuniones para convertirlas en un espacio de conexión entre ambas partes.

A continuación, os presento algunas ideas que yo misma he llevado a cabo en las reuniones con las familias de mis alumnos con unos resultados muy positivos.

1. Por equipos y siguiendo la técnica 1-2-4 de aprendizaje cooperativo, compartir qué esperan del cole ese curso y qué van a ofrecer ellos como familia. Dado el contenido tan interesante que puede generar, es recomendable realizarla a principios de curso.

2. También por equipos y utilizando la rutina de pensamiento "veo - pienso - me pregunto", analizar cómo está siendo el funcionamiento del curso en base a determinados puntos planteados por el tutor. En este caso, esta dinámica resultará efectiva en la reunión de padres de mediados de curso.

3. Realizar un acuerdo emocional entre las familias y el centro con lo que ellos quieren o desean sentir respecto al centro y lo que pueden hacer para lograrlo. En este caso, también sería recomendable realizarla a principios de curso.

4. Representar de forma creativa y utilizando diferentes materiales cómo se sienten durante el curso, qué dificultades tienen, cuál es su grado de satisfacción y qué propuestas de mejora pueden aportar. Esta dinámica también está enfocada a hacer una revisión del curso, por lo que debería llevarse a cabo en una segunda reunión.

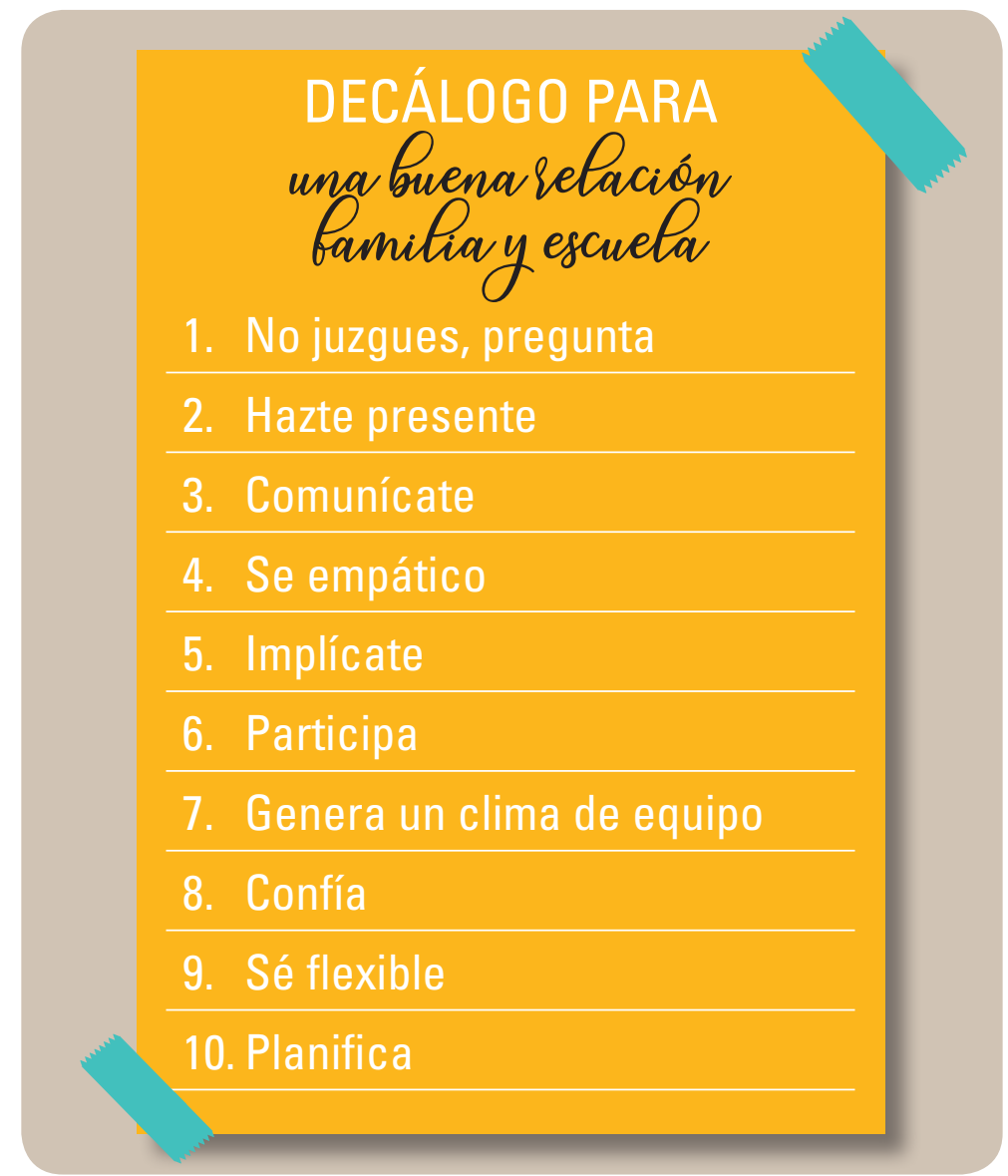


En unas condiciones sanitarias seguras, sería ideal poder realizar un taller donde los tres agentes estuviesen implicados: alumnos, familias y docentes. De ese modo, se podrían llevar a la práctica actividades como las que he propuesto en este artículo (con las adaptaciones necesarias) para generar un verdadero clima de equipo y de trabajo común. Todas las actividades están enfocadas a conocer más las realidades de las familias y de la escuela, a adentrarse un poco más en las vidas de padres, madres y docentes para despertar la empatía y la confianza mutua. Por todo ello, sería recomendable que se realizaran al principio del curso escolar 0 , al menos, durante el primer trimestre del mismo

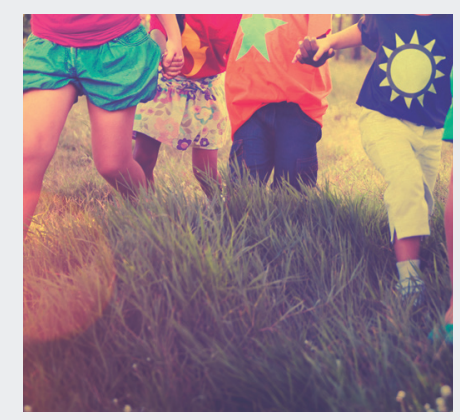

Como he repetido en numerosas ocasiones a lo largo del artículo, las familias tienen mucho que decir y mucho que aportar. Por ello, todas estas actividades están enfocadas a dar voz a las familias para afianzar sus puntos de unión con la escuela de sus hijos. Alguna de ellas puede resultar, quizás, un poco atrevida; pero estoy convencida de que funcionaría y cumpliría expectativas. Yo misma he llevado a cabo estas actividades con las familias de mis alumnos y los resultados han sido útiles, enriquecedores y muy emotivos.

1. Escribir una carta al tutor o tutora de su hijo durante la primera semana de curso. En esta carta, se presentarán como familia y profundizarán en su hijo. Hablarán de cómo es como persona, de su historia, de las cosas que le gusta hacer en su tiempo libre, de sus experiencias previas en el cole, de sus amigos... Esta carta tiene un doble objetivo: invitar a las familias a reflexionar sobre su propio hijo y ayudar a su tutor a que le conozca mucho mejor y de una forma muy especial.

2. Preparar una entrevista para el tutor o tutora de su hijo y llevarla a cabo en la reunión de padres al inicio del curso. No solo tenemos que conocer a las familias desde el cole, sino que ellas también necesitan conocernos a nosotros, los docentes. Siempre desde el respeto y centrados en la parte profesional, el tutor puede responder a las posibles curiosidades 0 inquietudes que tengan las familias. El docente debe mostrarse abierto y confiado.

3. Realizar un vídeo donde presenten a toda la familia y las cosas que les gusta hacer juntos. Ese vídeo se puede visualizar en clase con los alumnos 0, incluso, en una reunión de padres en la que participen grandes y pequeños. Es necesario cuidar esa posible brecha social o tecnológica y prestar atención para que todas las familias tengan las mismas oportunidades. Pero puede ser una ocasión perfecta para que todos se conozcan y empezar a generar un clima de equipo.
Del mismo modo que afirmaba respecto al cuestionario 2, coincido de nuevo en que estas conclusiones son aplicables a cualquier contexto escolar sin un virus de por medio. Considero que la verdadera innovación educativa debe pasar por una relación de calidad entre las familias de nuestros alumnos y la escuela. Este virus ha venido a enseñarnos, a transformarnos. Aprovechemos esta valiosísima oportunidad para revolucionar la escuela. Las familias no se pueden seguir quedando al margen. Los docentes no podemos seguir quejándonos de que una familia reclama o que una familia exige. Es cierto que lo hacen, claro, como lo han hecho siempre. Pero el verdadero contexto educativo de nuestros alumnos está compuesto por sus familias y su centro escolar. Es hora de llevar a cabo un verdadero trabajo en equipo. Desde mi experiencia puedo asegurar que la satisfacción que se siente por el éxito de un buen trabajo realizado conjuntamente es lo que me hace seguir aprendiendo, seguir formándome y seguir esforzándome día a día. Este trabajo en equipo es la verdadera clave de mi vocación de maestra.

La gratitud es un gran valor perdido para algunos, pero un gran valor siempre presente para mí. Así, manifiesto mi profundo agradecimiento a cada una de las familias de mis alumnos haciéndolo de este modo recíproco. Su comprensión, su apoyo e incluso su admiración por la labor que todos los maestros realizamos es el fruto de haber sembrado en ellos una semilla de confianza y cercanía

\section{HEMOS HABLADO DE}

\section{Aprendizaje a distancia; experiencia docente; proceso de aprendizaje; adaptación; relación familia y escuela.}

Este artículo fue solicitado por PADRES Y MAESTROS en mayo de 2020, revisado y aceptado en octubre de 2020. 